\title{
In vitro gastrointestinal digestion study of a novel bio-tofu with special emphasis on the impact of microbial transglutaminase
}

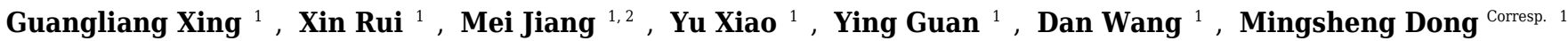 \\ ${ }^{1}$ College of Food Science and Technology, Nanjing Agricultural University, Nanjing, P. R. China \\ 2 Huai'an academy of Nanjing Agricultural University, Huai'an, P. R. China \\ Corresponding Author: Mingsheng Dong \\ Email address: dongms@njau.edu.cn
}

We have developed a novel bio-tofu, made from mixed soy and cow milk (MSCM) using Lactobacillus helveticus MB2-1 and Lactobacillus plantarum B1-6 incorporated with microbial transglutaminase (MTGase) as coagulant. MTGase was added to improve the textural properties and suit for cooking. But the effect of MTGase on mixed-protein fermented by lactic acid bacteria was unclear. This study aimed at evaluating the effect of MTGase on protein digestion of bio-tofu under simulated gastrointestinal digestion condition. The results showed that addition of MTGase could affect the particle size distribution, degree of hydrolysis, the content of soluble proteins and free amino acids. Based on the electrophoresis data, MTGase addition enhanced protein polymerization. During gastric and intestinal digestion process, proteins from bio-tofu were degraded into low molecular mass peptides. Our results suggested that incorporation of MTGase could lead to enzymatic modification of proteins of bio-tofu which may help in controlling energy intake and decrease the chance of food allergy. 
1 In vitro gastrointestinal digestion study of a novel bio-tofu with special emphasis on the impact of microbial transglutaminase

3

4 Guangliang Xing ${ }^{1}$, Xin Rui ${ }^{1}$, Mei Jiang ${ }^{1,2}$, Yu Xiao ${ }^{1}$, Ying Guan ${ }^{1}$, Dan Wang ${ }^{1}$,

$5 \quad$ Mingsheng Dong ${ }^{1, *}$

6

$7{ }^{1}$ College of Food Science and Technology, Nanjing Agricultural University, Nan Jing,

8 Jiangsu Province, P R China

$9 \quad{ }^{2}$ Huai'an academy of Nanjing Agricultural University, Huai'an, Jiangsu Province, P R

10 China

*Corresponding author contact information:

Mingsheng Dong

College of Food Science and Technology

Nanjing Agricultural University

1 Weigang Road, Nanjing, Jiangsu, P.R. China

Tel: +86 2584396989

Fax: +86 2584399090

E-mail address: dongms@njau.edu.cn

23

PeerJ reviewing PDF | (2016:07:12397:1:0:NEW 15 Oct 2016) 
24

\section{Abstract}

We have developed a novel bio-tofu, made from mixed soy and cow milk (MSCM) using Lactobacillus helveticus MB2-1 and Lactobacillus plantarum B1-6 incorporated with microbial transglutaminase (MTGase) as coagulant. MTGase was added to improve the textural properties and suit for cooking. But the effect of MTGase on the digestion of mixed-protein fermented by lactic acid bacteria was unclear. This study aimed at evaluating the effect of MTGase on protein digestion of bio-tofu under simulated gastrointestinal digestion condition. The results showed that addition of MTGase could affect the particle size distribution, degree of hydrolysis, the content of soluble proteins and free amino acids. Based on the electrophoresis data, MTGase addition enhanced protein polymerization. During gastric and intestinal digestion process, proteins from bio-tofu were degraded into low molecular mass peptides. Our results suggested that incorporation of MTGase could lead to enzymatic modification of proteins of bio-tofu which may help in controlling energy intake and decrease the chance of food allergy.

Keywords: Bio-tofu; lactic acid bacteria; microbial transglutaminase (MTGase); In vitro gastrointestinal digestion 


\section{Manuscript to be reviewed}

42

43

44

45

46

47

48

49

\section{Introduction}

Tofu (soybean curd) is a gel-like food that widely consumed in Asia counties.

Conventional tofu is made by coagulating heated soymilk with salt coagulants, like magnesium chloride and calcium sulfate, followed by moulding and pressing the curd to draw the whey. Besides, microbial transglutaminase (MTGase) and glucono- $\delta$-lactone (GDL) have also been used to prepare tofu over the last two decades. Different kinds of coagulant can influence the yield and quality of the final products, for example, the texture of tofu coagulated by GDL and $\mathrm{CaSO}_{4}$ was smoother, while the texture of tofu coagulated by $\mathrm{MgCl}_{2}$ was harder (Hou et al., 2016). Additionally, the addition of MTGase can help maintain the smooth texture of tofu (Yokoyama, Nio, \& Kikuchi, 2004). However, a single protein source of soymilk has been unsatisfied people's nutritional needs, the production of mixed protein matrix is an area of great potential for future development.

Composite gels containing casein (the main cow milk proteins) and soy proteins are possible to be obtained according to the previous studies (Grygorczyk et al., 2014; Lin, Hill, \& Corredig, 2012). Formulations containing both soymilk and cow milk proteins provide additional health benefits and also show great potential for new category of food products. The present work focused on a novel soymilk and cow milk mixed tofu, named as bio-tofu, by means of lactic acid bacteria (LAB) incorporated with microbial transglutaminase (MTGase) instead of bittern as coagulant. MTGase (EC 2.3.2.13) is an enzyme that catalyzes the transfer reaction between many proteins by crosslinking of the amino acid residues of protein bound 
64 glutamine and lysine. (Hsieh et al., 2014). Soy proteins and caseins are known to be good substrates for MTGase. Enzymatic modification of proteins by MTGase provides protein to distribute more homogeneously and evenly in network which increases the gel stability and in turn affects the techno-functional properties. Thus, there are numerous health benefits associated with the consumption of bio-tofu containing both proteins and probiotic, and such gels would deliver the health benefits of both dairy and soy products.

It turned out that it's an effective technique of MTGase cross-linking which can be used to improve surface hydrophobic and mechanical properties of protein films, i.e. gelation, emulsification, viscosity and foaming (Romano et al., 2016). Particularly, MTGase used in food stuff may modify the immunogenicity of food proteins, such as soy proteins (Babiker et al., 1998), peanut proteins (Clare, Gharst, \& Sanders, 2007) and fermented milk beverages (Wróblewska et al., 2013). However, the resistant ability of food proteins to the gastrointestinal enzymes is an important factor to take into account which is related to immunological assays (Villas-Boas et al., 2012). In some cases the MTGase-catalyzed reaction can affect the stability of proteins with respect to their bioaccessibility (Rui et al., 2016), digestibility and allergenicity (Stanic et al., 2010; Tang et al., 2008). Moreover, Monogioudi et al. (2011) reported that none crosslinked $\beta$-casein was less resistant to pepsin digestion when compared to cross-linking of $\beta$-casein by MTGase. According to these findings mentioned above, the novel food structures with improved properties such as controlled energy intake, good satiety and digestibility may develop rapidly in the future. Thus, enzymatic 
86

87

88

89

90

modification of proteins by MTGase could lead to firmer matrices that are digested to a lower extent which may help in controlling energy intake.

Although the study of milk and soy proteins have been conducted, little information is available on the properties of the mixed gels, expecially about the interactions between soymilk and cow milk proteins during acid- (fermented by lactic acid bacteria) and MTGase-induced aggregation. Because of MTGase was used in the present study, it's necessary to determine the digestibility and stability of mixed-proteins through gastrointestinal digestion. The objective of this work was to determine the changes of proteins that take place on addition of MTGase or not to mixed soymilk and cow milk fermented by Lactobacillus helveticus MB2-1 and Lactobacillus plantarum B1-6 at different points and evaluate the protein degradation and release of peptides/amino acids of bio-tofu by an in vitro gastrointestinal digestion (GIS) model.

\section{Materials and Methods}

\subsection{Materials}

a-Amylase (A1031), pepsin (P7000), bile acid (B8631), pancreatin (P3292) were purchased from Sigma-Aldrich Co. (St. Louis, MO, USA). Molecular mass standard (15-150 kDa) was purchased from Sangon Biotech Co. (Shanghai, China). All other regents used were of analytical grade.

\subsection{Preparation of bio-tofu}

L. helveticus MB2-1 and L. plantarum B1-6 were isolated in our lab from Sayram ropy fermented milk and Kirgiz boza respectively, which are all traditional 


\section{Manuscript to be reviewed}

108 food collected from Xinjiang province of China (Li et al., 2012; Wu et al., 2015). $L$.

109 helveticus MB2-1 had been deposited in the Gen Bank database with accession

110 number CP011386 and L. plantarum B1-6 was given a gene accession number

111 KM200717. L. plantarum B1-6 strains were activated twice in de Man-Rogosa and

112 Sharp broth (MRS, pH $6.2 \pm 0.2$, Oxoid-CM0361, Unipath, Basingstoke, UK) at $37{ }^{\circ} \mathrm{C}$

113 for $24 \mathrm{~h}$ and $16 \mathrm{~h}$ prior to use. L. helveticus MB2-1 strains were propagated for two

114 successive transfers in cow milk (Mengniu Dairy Group, China, total fat-3.7 $\mathrm{g}$, total

115 carbohydrate $-4.8 \mathrm{~g}$, protein-3.0 g per $100 \mathrm{ml}$ ) at $42{ }^{\circ} \mathrm{C}$ for $24 \mathrm{~h}$ and $16 \mathrm{~h}$ prior to use

116 in experimental trials.

117 The step-by-step preparation of bio-tofu is shown in Fig. 1. Briefly, soaked

118 soybeans were ground twice at high speed for 5 min by homogenizer (BE601AB,

119 Midea, China) with hot water $\left(90-95{ }^{\circ} \mathrm{C}\right)$ at a bean:water ratio of $1: 9(\mathrm{~m} / \mathrm{v})$. After

120 grinding, a 200-mesh screen cloth was used to remove the okara, which was mainly

121 insoluble fibre. Then the raw soymilk was obtained. Subsequently, this soymilk was

122 mixed with cow milk for a final protein content of $1.6 \%$ milk protein and $1.6 \%$ soy

123 protein in the mixture. The resultant mixed-liquid was heated in a pan, with constant

124 stirring at $100{ }^{\circ} \mathrm{C}$, on a Joyoung induction cooker (C21-QPAD1, Hangzhou, China)

125 for about $5 \mathrm{~min}$. After cooling to incubation temperature $\left(38-40{ }^{\circ} \mathrm{C}\right)$, the mixed soy

126 and cow milk (MSCM) were inoculated with $4.0 \%(\mathrm{v} / \mathrm{v})$ of a mixed culture $(1: 1 \mathrm{v} / \mathrm{v})$

127 of L. plantarum B1-6 and L. helveticus MB2-1. Subsequently, MTGase (110 U/g) was

128 added into the solution with stirring at concentration of $3.0 \mathrm{U} / \mathrm{g}$ (based on the content

129 of protein). Inoculated MSCM with adding MTGase were poured into many $100 \mathrm{~mL}$

Peer) reviewing PDF | (2016:07:12397:1:0:NEW 15 Oct 2016) 
130 sterile cups and incubated at $38{ }^{\circ} \mathrm{C}$ for $5 \mathrm{~h}$ to make bio-tofu (BT-with MTGase). In

131 the production of samples, the same procedure mentioned above were followed but

132 without adding MTGase to form another kind of curd (BT-without MTGase). After

133 incubation, all samples were cooled down and stored at $4{ }^{\circ} \mathrm{C}$ for analysis.

134

135

\subsection{In vitro GIS digestion}

The in vitro buccal, gastric and intestinal juice was prepared as described by Shim et al. (2010) with some modifications to mimic human digestion. The whole GIS digestion steps were carried out sequentially in beakers placed in a shaking water bath (SWB series, Biobase, Shandong, China) at $37{ }^{\circ} \mathrm{C}$ which is shown in Fig. 2. Several GIS digestions of both BT-with MTGase and BT-without MTGase were performed to obtain digested samples at different times during the digestion process. The digestion times studied were as follows: before digestion (P0); at the end of buccal phase (3 min, P1); after 1, 5, 25 and 60 min of gastric phase (P2-1, P2-5, P2-25, P2-60) and after 1, 5, 30, 120 min of duodenal phase (P3-1, P3-5, P3-30, P3-120). After each digestion time, each sample was heat-treated at $95{ }^{\circ} \mathrm{C}$ for 5 min to stop the enzymatic digestion and then centrifuged (CT15RT, $10000 \times \mathrm{g}, 20 \mathrm{~min}, 4{ }^{\circ} \mathrm{C}$ ) except those prepared for particle size distribution. The supernatants were kept frozen at $-20{ }^{\circ} \mathrm{C}$ until use.

\subsection{Particle-Size Distribution}

The particle-size distribution of the digestion samples was determined using a Mastersizer 3000 (Malvern Southborough, MA). A particle refractive index of 1.39 was used for caseins, 1.46 for soy proteins dispersions and 1.42 for the mixed systems 


\section{Manuscript to be reviewed}

152 (Lin, Hill, \& Corredig, 2012). The refractive index of the dispersing phase (water)

153 was 1.33 . The volume-weighted mean diameter D [4,3] was characterized as the size

154 of gel particles. D [v,0.90] was also reported to describe the diameter below which $90 \%$

155 of the volume of particles were found. The analysis was conducted in triplicates.

156

157

158

159

160

161

162

163

164

165

166

167

168

169

170

171

172

173

\subsection{Total soluble protein content of digested samples}

Soluble protein in the supernatants from digested BT-with MTGase and BT-without MTGase were quantified with the Bradford method (Bradford, 1976) using bovine serum albumin (Sigma) as the standard. A microplatereader (VersaMax ELISA Microplate Reader, Molecular Devices, USA) was used to determine the concentration spectrophotometrically $(595 \mathrm{~nm})$. The soluble protein content in the supernatant of digestion mixtures was expressed as milligram protein in per milliliter GIS digestion fluid (mg/mL). Each sample was analyzed in triplicates.

\subsection{Electrophoresis}

Aliquots taken at different digestion time points were evaluated by sodium dodecyl sulfate-polyacrylamide gel electrophoresis (SDS-PAGE), which was conducted at presence of $5 \% \beta$-mercaptoethanol by using a $12 \%$ polyacrylamide gel. The gels were stained with $0.1 \%(w / v)$ Coomassie brilliant blue R-250 (Sigma) at room temperature. SDS-PAGE was conducted on a Bio-Rad Miniprotein 3 unit (Bio-Rad Laboratories, Inc., Hercules, CA, USA) with voltage $60 \mathrm{~V}$ for stacking gel, and followed by $120 \mathrm{~V}$ for separating gel. The molecular weight values of the protein fractions were estimated using broad-range Protein Marker (15-150 kDa). The protein-stained bands were scanned with Image Scanner III (GE Healthcare 


\section{Manuscript to be reviewed}

174 Biosciences, Uppsala, Sweden) and analyzed using Quantity One software, version 175 4.6.2 (Bio-Rad Laboratories, Inc., Hercules, CA, USA).

176

177

178

179

180

181

182

183

184

185

186

187

188

189

190

191

192

193

194

195

\subsection{Degree of hydrolysis}

The determination of the degree of hydrolysis $(\mathrm{DH})$ during in vitro GI digestion was carried out using the o-phthaldialdehyde (OPA) method by Church et al. (1983). Briefly, $400 \mu \mathrm{L}$ of the supernatant was added to $3 \mathrm{~mL}$ of OPA reagent and left at room temperature for $2 \mathrm{~min}$. After $2 \mathrm{~min}$, the absorbance of the solution was measured using a spectrophotometer at $340 \mathrm{~nm}$. Serine was used as a standard, measurements were realized in duplicates.

\subsection{Protein digestibility assay $-\mathrm{pH}$ drop method}

The $\mathrm{pH}$ drop method was used to determine the rate of digestibility of the BT-with MTGase and BT-without MTGase according to previous study (Hsu et al., 1977). Digestibility of each sample was calculated based on the change in $\mathrm{pH}$ after 10 min of digestion $(\mathrm{X})$ using the equation: Digestibility= 210.46-18.10X. The analysis was conducted in triplicates.

\subsection{Free amino acid determination}

Free amino acid determination was analyzed according to a previous procedure (Aro et al., 2010). Samples collected at varied digestion times were mixed with $4 \%$ trichloroacetic acid (TCA) at volume ratio of $1: 1$ and then incubated at $37{ }^{\circ} \mathrm{C}$ for 30 min. The mixture was subsequently filtered using a $7 \mathrm{~cm}$ Whatman filter paper disc, and the filtrates collected were further applied to $0.45 \mu \mathrm{m}$ filters. $20 \mu \mathrm{l}$ of the sample were subjected to a fully automated amino acid analyser HITACHI L-8900 (Hitachi 


\section{Manuscript to be reviewed}

196 Ltd., Japan).

197

198

199

200

201

202

203

204

205

206

207

208

209

210

211

212

213

214

215

216

217

\subsection{Statistical analysis}

The data were subjected to independent student's t-test to determine the significant difference between means at $\mathrm{P}<0.05$ level using IBM SPSS Statistics.

\section{Results and discussion}

\subsection{Particle size distribution}

The particle size distribution of the BT-with MTGase and BT-without MTGase before and after in vitro gastrointestinal digestion are shown in Fig. 3. The figures clearly suggest a bimodal distribution for BT-with MTGase with a size range from 5.92 to $454 \mu \mathrm{m}$ and BT-without MTGase with a size range from 4.58 to $352 \mu \mathrm{m}$ (Fig. 3A). The particle size (D[4,3]) in BT-with MTGase and BT-without MTGase were significantly different $(\mathrm{P}<0.05)$. Besides, BT-with MTGase had larger value of $\mathrm{D}[\mathrm{v}, 0.90](236.33 \pm 2.31 \mu \mathrm{m})$ which indicated a tight and compact structure of proteins obtained through cross-linking by MTGase. Nevertheless, the addition of simulated saliva fluid to the two samples led to the particle size distribution increased remarkably (Fig. 3B). This might due to proteins precipitation during the heat-treatment of stopping the $\alpha$-Amylase digestion process. The subsequent in vitro gastric digestion (P2) altered larger protein particles to smaller ones which appeared as a result of the breakdown by pepsin (Fig. 3C). Meanwhile, a decrease of the volume mean $\mathrm{D}[4,3]$ diameter was also detected. The phenomenon was particularly observed for BT-with MTGase, as indicated by $\mathrm{D}[4,3]$ value reduced from $163.00 \pm 6.24 \mu \mathrm{m}(\mathrm{P} 1)$ to $24.60 \pm 2.05 \mu \mathrm{m}$ (P2) (Fig. 3B, C). After $120 \mathrm{~min}$ of duodenal 


\section{Manuscript to be reviewed}

218 phase, the size shift rate of these two samples was slower, but a higher level of much

219 smaller particles $(<10 \mu \mathrm{m})$ was generated (Fig. 3D). BT-with MTGase contained 220 larger $\mathrm{D}[4,3]$ and $\mathrm{D}[\mathrm{v}, 90]$ values compared to BT-without MTGase. This observation

221 also showed that large protein particles were harder to break down by the digestive

222 enzymatic which were assembled by MTGase. The MTGase cross-linking influenced

223 the gastric and duodenal digestibility of BT-with MTGase, making the protein digest

224 slower than BT-without MTGase.

\subsection{Protein degradation under simulated gastrointestinal digestion condition}

Fig. 4 shows the soluble protein content in the supernatants obtained from digestion of the mixed soy-cow protein samples. Due to the presence of digestive enzymes, the amounts of soluble proteins changed obviously. Before digestion ( $\mathrm{P} 0)$, low amounts of soluble proteins were detected for both BT-with MTGase and BT-without MTGase. No change of solubilization of proteins in BT-without MTGase at the buccal digestion (P1) phase but a slight increase in that of BT-with MTGase. During the subsequent gastric digestion, the protein solubility in both samples were increased drastically. The amounts of soluble proteins of BT-with MTGase and BT-without MTGase increased sharply to $2.35-3.11 \mathrm{mg} / \mathrm{mL}$ and $5.03-5.56 \mathrm{mg} / \mathrm{mL}$ dramatically due to the gastric environment, including the acidic $\mathrm{pH}$, the presence of pepsin and continuous mechanical shaking. Those results were in accordance with the respectively, which could be explained by the hydrolytic action of pepsin. The organized protein network collapsed quickly and soluble proteins released studies of Rinaldi et al. $(2014,2015)$. Protein solubility peaked at $5 \mathrm{~min}$ and $60 \mathrm{~min}$ of 


\section{Manuscript to be reviewed}

240 gastric digestion for BT-without MTGase and BT-with MTGase, respectively. During

241 the duodenal digestion phase (P3), the pattern changed and resulted in the decrease of 242 the soluble protein content for both samples. The formation of peptides and amino 243 acids during P3 had lower molecular masses which were undetected by Bradford 244 assay, thus underestimated results were observed. Similar observations were reported 245 by Rioux \& Turgeon (2012) to determine the effects of milk protein composition on in vitro digestion. Overall, the dilution related to the addition of the duodenal solution,

247 the $\mathrm{pH}$ changes and the rapid hydrolysis resulted in similar decrease values for both samples.

The amounts of soluble proteins changed as a result of the hydrolysis initiated by proteolytic enzymes in the process of digestion. However, the addition of MTGase had remarkable influences on the in vitro digestibility of protein. Similar observation was also reported which showed that the presence of MTGase would retard the rate of digestion in an in vitro gastric digestion (Macierzanka et al., 2012), even through with different concentrations (Rui et al., 2016). This was probably due to the formation of cross-linking bonds among proteins made it more difficult for enzymes in the digestive fluid to attack, which led to much fewer proteins digested. So the food microstructure had an impact on the solubilization of proteins or their hydrolysis

258 during the GIS digestion. In addition, these results could be exploited in novel food matrices that, because of its lower digestibility by adding MTGase, could provide commercial products with controlled energy intake (Romano et al., 2016). 

were analyzed by Quantity One software. The results of relative quantity were found within the table below the Fig. 5A and B. glycinin (11S). $\beta$-Conglycinin is a trimer formed from various combinations of the three subunits $\left(\alpha^{\prime}, \alpha\right.$, and $\left.\beta\right)$ and $11 \mathrm{~S}$ is a hexameric protein consisting of six subunits (Aguirre et al., 2014). The major proteins of cow's milk are casein and whey. Five different forms were contained in casein $\left(\alpha_{\mathrm{s} 1}-\mathrm{CN}, \alpha_{\mathrm{s} 2}-\mathrm{CN}, \beta-\mathrm{CN}, \gamma-\mathrm{CN}\right.$, and $\left.\kappa-\mathrm{CN}\right)$ and whey has two subunits [ $\alpha$-lactalbumin ( $\alpha$-LA) and $\beta$-lactoglobulin $(\beta$-LG)] (Chen et al., 2012). No significant changes were observed in BT-without MTGase after a 5-h incubation (Fig. 5B), indicating that proteolysis during fermentation by L. helveticus MB2-1 and L. plantarum B1-6 were not intense. Besides, protein polymerization did not occur in the absence of MTGase. Whereas cross-links between soymilk and cow milk proteins were seen to form during fermentation in the presence of MTGase (Fig 5A). A concurrent increase in high-molecular-mass polymer(s) was/were observed which correlated positively with increasing incubation time. Moreover, the SDS-PAGE profiles of the BT-with MTGase showed a progressively decrease in the intensities of both soymilk protein (7S and 11S) and cow milk protein (casein and $\beta$-lactoglobulin) bands. In particular, the intensity of the $\alpha^{\prime}, \alpha, \beta$ subunits of 


\section{Manuscript to be reviewed}

284 the least reactive. It was noteworthy that the majority of the $11 \mathrm{~S}$ A3 subunit 285 disappeared after a 1-h incubation period (Fig. 5A), showing that the enzymatic reactivity for the 11S A3 subunit was much higher than that for other $11 \mathrm{~S}$ acidic proteins. This observation was in agreement with the results reported by Yasir et al. (2007). Most likely, the 11S A3 subunit is located on the surface of the $11 \mathrm{~S}$ molecule thus is the most accessible and reactive monomer that can be attacked by MTGase more easily.

SDS-PAGE separated the major cow milk proteins, including the $\alpha-\mathrm{CN}, \beta-\mathrm{CN}$, $\kappa-\mathrm{CN}$ and $\beta$-LG as shown in Fig. 5. The molecular weight of each protein was 33.4, 27.3, 24.7 and $17.0 \mathrm{kDa}$, respectively. The bands corresponding to casein fractions became less intense as the incubation time increased (Fig. 5A). Compared with casein, the $\beta$-LG acted less effectively. It had been reported that whey proteins had lower tendency to form cross-link reaction than caseins by MTGase (Şanlı et al., 2011). In general, the native fold of the proteins (Tang et al., 2006) and the amino acid sequence specificity of MTGase (Kamiya et al., 2003) related to the differences in reactivities of the subunits.

The identification of the soluble proteins found in the supernatant during in vitro GIS were further visualized as shown in Fig. 6 A and B. A limited number of bands with molecular mass (MM) of 38 and $30 \mathrm{kDa}$ (band 1 and 2, Fig. 6A) were detected in the supernatant of BT-with MTGase at P0 phase which was in agreement with the earlier finding of low soluble protein content. After buccal digestion (lane P1, Fig 6A), the pattern was unchanged since there were no proteases in buccal fluids. Upon 


\section{Manuscript to be reviewed}

306 digestion of pepsin (lane P2, Fig 6A), revealing the existence of resolved protein 307 bands ranging from $22-33 \mathrm{kDa}$ (band 3), $\beta$-LG at $17 \mathrm{kDa}$ (band 4). The band 3 and 4 308 were stable at all time points of pepsin digestion. The band 3 appeared to be partially 309 hydrolyzed while still visible at P2-60. In terms of band 4, $\beta$-LG was resistant to 310 enzymatic digestion, particularly to pepsin, which was interrelated to its complex 311 structure in acidic pH (Chicón et al., 2008). During the duodenal digestion phase (lane 312 P3, Fig 6A), band $3(21-30 \mathrm{kDa})$ were stable while band 4 was undetected at $1 \mathrm{~min}$ 313 time point compared to the $17 \mathrm{kDa}$ band which could be seen in the lane $\mathrm{P} 2$, as in 314 findings by Do, Williams \& Toomer (2016). Meanwhile, an indeterminate smear (lane shown in Fig. 6B. AS shown in lane P2 (Fig. 6B), protein bands of $76 \mathrm{kDa}$ (band 1), $56 \mathrm{kDa}$ (band 2) were not exsit in lane P2 of Fig. 6A, but these two samples had the same MM range from 22-33 kDa (band 3). The band 3 (lane P2 and P3, Fig. 6B) were stable at all time points of gastric and duodenal digestion. It is thought that in order to reach the immune system of the intestine, an allergen is able to survive harsh acidic and proteolytic environment of the stomach, or to share the epitopes with common aeroallergens (Mills et al., 2004). Thus, the more proteins bands were detected through the gastrointestinal digestion, the bigger chance of being an allergen. 
328 (lane P2, Fig 6B). Besides, gastric digestion allowed the presences of more visible 329 bands in BT-without MTGase than BT-with MTGase (i.e., the band 1 and 2 in lane P2 Fig. 6B couldn't be observed in lane P2 Fig. 6A). Under the hydrolysis of pepsin, some new bands were detected which were not existed in the original soy milk and cow milk profile. This pattern maintained through the gastric digestion for these two samples. During the duodenal digestion phase, the patterns were similar throughout digestion but more intensive bands were observed in the low molecular mass region, which might reflect a rapid degradation of protein. Proteins had been degraded further into fragments of lower molecular mass which were not detected by SDS-PAGE. In general, the enzymatic modification of soy and cow milk proteins by MTGase could lead to firmer matrices that were digested to a lower extent which indicated the less chance to induce food allergy.

\subsection{Digestibility determined by $\mathrm{pH}$ drop methods and the degree of hydrolysis}

Table 1 shows the in vitro protein digestibility of these two mixed soy-cow

342 protein samples. It was found that BT-without MTGase showed significantly higher value $(\mathrm{P}<0.05)(74.65 \pm 0.75 \%)$ than BT-with MTGase $(72.18 \pm 0.58 \%)$. The protein digestibility results indicated that BT-without MTGase was much more susceptible to digestive enzymes, whereas strong inter/intra molecular bonds were formed by digestive enzymatic hydrolysis. 
350 duodenal digestion (P3-1, P3-120) which are shown in Fig. 7. During GIS digestion,

351 soy proteins and cow milk proteins were degraded by pepsin and pancreatin, resulting

352 in the release of various forms of peptides and free amino groups. As depicted in Fig.7,

353 initiating of gastric digestion for $1 \mathrm{~min}(\mathrm{P} 2-1)$ resulted in a dramatically elevation of

354 the DH level which indicated many proteins were hydrolyzed into large peptides by

355 pepsin. At the end of gastric digestion (P2-60), the DH of the BT-without MTGase

$356(16.36 \%)$ was significantly higher $(\mathrm{P}<0.05)$ than BT-with MTGase $(11.49 \%)$. The

357 DH slightly increased for these two samples at the beginning of duodenal digestion.

358 At the end of the whole digestion, BT-without MTGase still showed dramaticlly

359 higher DH $(21.55 \%)$ than BT-with MTGase $(16.30 \%)(\mathrm{P}<0.05)$. In general, a fast

360 hydrolysis and an increase in the number of low molecular mass peptides at each

361 digestion step contributed to the increase of the DH level.

362

363

364

365

366

367

368

369

370

371

\subsection{Amino acids analysis}

At the end of in vitro GIS digestion, the content of free amino acids (FAA) in the two samples was measured and the results are shown in Table 2. The presence of peptidases in pepsin and pancreatin added in digestion juice resulted in a considerable increase of FAA content in both samples. As shown in Table 2, eighteen amino acids were determined and eight of them were corresponding to essential amino acids (Thr, Val, Met, Ile, Leu, Phe, Lys and Trp). The concentration of total FAA content in BT-without MTGase $(81.671 \mathrm{mg} / \mathrm{L})$ was 1.69-fold higher than BT-with MTGase $(48.400 \mathrm{mg} / \mathrm{L})$.

At the end of digestion, the most abundant amino acids released (in milligrams 


\section{Manuscript to be reviewed}

372 per liter) in BT-without MTGase were Arg (14.827), Glu (10.050), Phe (9.774), Tyr

373 (9.537), and Pro (8.738), followed by Ala (5.956), Lys (4.697), Leu (3.352), and His

374 (3.165), together representing $85.83 \%$ of total FAA. The content of most essential

375 FAA (Thr, Ile, Phe, Lys, Trp) in BT-with MTGase were much lower than BT-without

376 MTGase, but only a few of them (Val and Leu) were slightly higher.

377 The content of FAA also reflected the SDS-PAGE patterns obtained in the end of 378 the in vitro GIS digestion for the samples. The SDS-PAGE pattern of BT-with 379 MTGase revealed fewer faint bands when compared to BT-without MTGase in the 380 low molecular weight region and this suggested that protein material was intensively 381 hydrolyzed as short peptides and FAA which were not retained by the gels. At the end 382 of the duodenal phase, the amount of peptides bands appeared in the low molecular 383 weight region of the gels followed the same increasing order than the FAA content: 384 BT-without MTGase > BT-with MTGase. Thus, addition of MTGase to soy-cow milk 385 mixtures might help enhance satiety, control energy intake or lose weight.

\section{Conclusions}

In the present study we have developed a novel bio-tofu, made from mixed soy and cow milk (MSCM) using Lactobacillus helveticus MB2-1 and Lactobacillus plantarum B1-6 incorporated with microbial transglutaminase (MTGase) as coagulant. This kind of bio-tofu was a good source of protein and contained all eight essential amino acids. It was also an excellent source of iron and calcium. In addition, the use of probiotics in bio-tofu was highly beneficial to the human health. Investigation was 
394

395

396

397

398

399

400

401

402

403

404

405

406

407

408

409 or not to MSCM at different points and evaluate the protein degradation profiles by an in vitro gastrointestinal digestion (GIS) model. The protein hydrolysis in the gastric and duodenal digestion phases were different for BT-with MTGase compared to BT-without MTGase as expected. Addition of MTGase seemed to influence the proteins' behavior and then affected the digestibility. On the other hand, food structures with higher satiety effects and lower allerginicity might be produced via enzymatic cross-linking by MTGase. While only an in vitro digestibility model was used in the study to evaluate the protein degradation which might do not predict the protein stability in vivo. Further investigations are needed to elucidate whether MTGase affects the allergenicity of bio-tofu during digestion in allergic individuals or testes in an animal model.

\section{Acknowledgments}

This work was supported by the Scientific and Technical Project of Huai'an city, Jiangsu Province (NO. HAC2015020). This research was also supported by Jiangsu Collaborative Innovation Center of Meat Production and Processing, Quality and Safety Control. 


\section{Manuscript to be reviewed}

410

411

412

413

414

415

416

417

418

419

420

421

422

423

424

425

426

427

428

429

430

431

\section{References}

Aguirre L, Hebert EM, Garro MS, de Giori GS. 2014. Proteolytic activity of Lactobacillus strains on soybean proteins. LWT-Food Science and Technology 59(2):780-785.

Aro JMA, Nyam-Osor P, Tsuji K, Shimada KI, Fukushima M, Sekikawa M. 2010. The effect of starter cultures on proteolytic changes and amino acid content in fermented sausages. Food Chemistry 119(1):279-285.

Babiker EFE, Hiroyuki A, Matsudomi N, Iwata H, Ogawa T, Bando N, Kato A 1998. Effect of polysaccharide conjugation or transglutaminase treatment on the allergenicity and functional properties of soy protein. Journal of Agricultural and Food Chemistry 46(3):866-871.

Bradford MM. 1976. A rapid and sensitive method for the quantitation of microgram quantities of protein utilizing the principle of protein-dye binding. Analytical Biochemistry 72(1):248-254.

Chen FM, Lee JH, Yang YH, Lin YT, Wang LC, Yu HH, Chiang BL. 2014. Analysis of $\alpha$-lactalbumin-, $\beta$-lactoglobulin-, and casein-specific IgE among children with atopic diseases in a tertiary medical center in northern Taiwan. Journal of Microbiology, Immunology and Infection 47(2):130-136.

Chicón R, Belloque J, Alonso E, López-Fandiño R. 2008. Immunoreactivity and digestibility of high-pressure-treated whey proteins. International Dairy Journal $18(4): 367-376$.

Church FC, Swaisgood HE, Porter DH, Catignani GL. 1983. Spectrophotometric 


\section{Manuscript to be reviewed}

432

433

434

435

436

437

438

439

440

441

442

443

444

445

446

447

448

449

450

451

452

453

assay using o-phthaldialdehyde for determination of proteolysis in milk and isolated milk proteins. Journal of Dairy Science 66(6):1219-1227.

Clare DA, Gharst G, Sanders TH. 2007. Transglutaminase polymerization of peanut proteins. Journal of Agricultural and Food Chemistry 55(2):432-438.

Do $\mathrm{AB}$, Williams $\mathrm{K}$, Toomer OT. 2016. In vitro digestibility and immunoreactivity of bovine milk proteins. Food Chemistry 190:581-587.

Grygorczyk A, Duizer L, Lesschaeve I, Corredig M. 2014. Gelation of recombined soymilk and cow's milk gels: Effect of homogenization order and mode of gelation on microstructure and texture of the final matrix. Food Hydrocolloids 35:69-77.

Hou JJ, Yang XQ, Fu SR, Wang MP, Xiao F. 2016. Preparation of doublenetwork tofu with mechanical and sensory toughness. International Journal of Food Science \& Technology 51(4):962-969.

Hsieh JF, Yu CJ, Tsai TY. 2012. Proteomic profiling of the coagulation of soymilk proteins induced by magnesium chloride. Food Hydrocolloids 29(1):219-225. Hsieh JF, Yu CJ, Chang JY, Chen ST, Tsai HY. 2014. Microbial transglutaminase-induced polymerization of $\beta$-conglycinin and glycinin in soymilk: a proteomics approach. Food Hydrocolloids 35:678-685.

Hsu HW, Vavak DL, Satterlee LD, Miller GA. 1977. A multienzyme technique for estimating protein digestibility. Journal of Food Science, 42(5):1269-1273.

Kamiya N, Takazawa T, Tanaka T, Ueda H, Nagamune T. 2003. Site-specific cross-linking of functional proteins by transglutamination. Enzyme and Microbial 


\section{Manuscript to be reviewed}

454 Technology 33(4):492-496.

455 Li W, Mutuvulla M, Chen XH, Jiang M, Dong MS. 2012. Isolation and 456 identification of high viscosity-producing lactic acid bacteria from a traditional 457 fermented milk in Xinjiang and its role in fermentation process. European Food 458 Research and Technology 235(3):497-505.

459 Lin C, Hill A, Corredig M. 2012. Gelation of mixtures of soymilk and 460 reconstituted skim milk subjected to combined acid and rennet. Journal of Texture $461 \quad$ Studies 43(6):468-476.

462 Macierzanka A, Böttger F, Lansonneur L, Groizard R, Jean AS, Rigby NM, 463 Mackie AR. 2012. The effect of gel structure on the kinetics of simulated 464 gastrointestinal digestion of bovine $\beta$-lactoglobulin. Food chemistry 465 134(4):2156-2163.

466 Mills EC, Jenkins JA, Alcocer MJ, Shewry PR. 2004. Structural, biological, and 467 evolutionary relationships of plant food allergens sensitizing via the gastrointestinal 468 tract. Critical Reviews in Food Science and Nutrition 44(5):379-407.

469 Monogioudi E, Faccio G, Lille M, Poutanen K, Buchert J, Mattinen ML. 2011. 470 Effect of enzymatic cross-linking of $\beta$-casein on proteolysis by pepsin. Food $471 \quad$ Hydrocolloids 25(1):71-81.

472 Rinaldi L, Gauthier SF, Britten M, Turgeon SL. 2014. In vitro gastrointestinal 473 digestion of liquid and semi-liquid dairy matrixes. LWT-Food Science and Technology $474 \quad 57(1): 99-105$. 


\section{Manuscript to be reviewed}

476 peptides and amino acids from yogurt made with starch, pectin, or $\beta$-glucan. 477 International Dairy Journal 46:39-45.

Rioux LE, Turgeon SL. 2012. The ratio of casein to whey protein impacts yogurt 479 digestion in vitro. Food Digestion 3(1-3):25-35. Impact of transglutaminase treatment on properties and in vitro digestibility of white bean (Phaseolus vulgaris L.) flour. Food Research International 88(PartB):239-246. comparison study of bioaccessibility of soy protein gel induced by magnesiumchloride, glucono- $\delta$-lactone and microbial transglutaminase. LWT-Food Science and Technology 71(6):234-242.

Food Hydrocolloids 25(6):1477-1481. based in vitro digestion and fermentation model. Food Research International 43(1):40-45. 
499 of vicilin-rich kidney protein isolate: Influence on the functional properties and in 500 vitro digestibility. Food Research International 41(10):941-947. glycinin-rich and $\beta$-conglycinin-rich soy protein isolate gels induced by microbial

503

504

505

506

507

508

509

510

511

512

513

514

515

516

517

518

519

transglutaminase. Food Research International 39(1):87-97.

Villas-Boas MB, Fernandes MA, de Lima Zollner R, Netto FM. 2012. Effect of polymerization with transglutaminase on in vitro digestion and antigenicity of $\beta$-lactoglobulin. International Dairy Journal 25(2):123-131.

Wróblewska B, Kaliszewska - Suchodoła A, Kołakowski P, Troszyńska A. 2013. The effect of microbial transglutaminase on the immunoreactive and sensory properties of fermented milk beverages. International Journal of Food Science \& Technology 48(5):1007-1017.

Wu H, Rui X, Li W, Chen XH, Jiang M, Dong MS. 2015. Mung bean (Vigna radiata) as probiotic food through fermentation with Lactobacillus plantarum B1-6. LWT-Food Science and Technology, 63(1):445-451.

Yasir SBM, Sutton KH, Newberry MP, Andrews NR, Gerrard JA. 2007. The impact of Maillard cross-linking on soy proteins and tofu texture. Food Chemistry 104(4):1502-1508.

Yokoyama K, Nio N, Kikuchi Y. 2004. Properties and applications of microbial transglutaminase. Applied Microbiology and Biotechnology 64(4):447-454. 


\section{Manuscript to be reviewed}

520 List of Tables:

521 Table 1 In vitro digestibility of the bio-tofu with MTGase (BT-with MTGase) and

522 bio-tofu without MTGase (BT-without MTGase). Mean values of digestibility that do

523 not share the same letter are significantly different at $\mathrm{P}<0.05$. Triplicate samples

524 were measured from duplication.

525

526 Table 2 Free amino acids contents of bio-tofu with MTGase (BT-with MTGase) and

527 bio-tofu without MTGase (BT-without MTGase) at the end of in vitro GIS digestion.

528 Results are expressed in milligrams per liter digestion solution. $\mathrm{ND}^{\mathrm{a}}=$ not determined

529

530 List of Figures:

531 Fig. 1 Schematic diagram of making bio-tofu.

532

533 Fig. 2 The process of in vitro gastrointestinal simulated digestion (GIS).

534

535

Fig.3 Particle size distribution of the mixed soy-cow protein samples (A) before the

GIS digestion, (B) after buccal digestion, (C) after gastric digestion, (D) after intestinal digestion. Different patterns represented bio-tofu with MTGase (BT-with

538 MTGase, $\rightarrow$ ) and bio-tofu without MTGase (BT-without MTGase, $\longrightarrow-$ ). Data

539 are expressed as mean \pm SD from triplicate experiments. Different letters within the 540 same column indicate significant difference $(\mathrm{P}<0.05)$. 
542 Fig.4 Soluble protein content $(\mathrm{mg} / \mathrm{mL})$ of the mixed soy-cow protein samples 543 subjected to in vitro gastrointestinal simulated digestion (GIS): 1-before the GIS (P0); 544 2-after buccal digestion (P1); 3, 4 5, 6-represented samples taken at 1 min, 5 min, 25 $545 \min$ and 60 min of gastric digestion (P2); 7, 8, 9, 10- represented samples taken at 1 $546 \mathrm{~min}, 5 \mathrm{~min}, 30 \mathrm{~min}$ and $120 \mathrm{~min}$ of intestinal digestion (P3). Different patterns 547 represented the bio-tofu with MTGase (BT-with MTGase, $\square$ ) and bio-tofu without 548 MTGase (BT-without MTGase, $\square$ ).

Fig.5 Sodium dodecyl sulfate polyacrylamide gel electrophoresis (SDS-PAGE)

551

552

553

554

555

556

557

558

559

560

561

562

563

profiles of the soy-cow milk mixtures fermented with addition of MTGase (A) or not (B) for different periods from $0 \mathrm{~h}$ to $5 \mathrm{~h} .7 \mathrm{~S} \alpha^{\prime}-$, $7 \mathrm{~S} \alpha$ - and $7 \mathrm{~S} \beta$-: subunits of $\beta$-conglycinin; 11S A3, 11S A1A2A4 and 11S Basic: acidic and basic subunits of glycinin; $\alpha-\mathrm{CN}, \beta-\mathrm{CN}$ and $\kappa-\mathrm{CN}$ of casein; $\beta-\mathrm{LG}$ of whey protein. Relative quantity (\%) of every protein band was found within the table.

Fig.6 Sodium dodecyl sulfate polyacrylamide gel electrophoresis (SDS-PAGE) analysis of digested samples before the GIS digestion (P0), during buccal (P1), gastric (1 min: P2-1, 5 min: P2-5, 25 min: P2-25, 60 min: P2-60) and duodenal (1 min: P3-1, 5 min: P3-5, 30 min: P3-30, 70 min: P3-70, 120min: P3-120) phases of in vitro GIS digestion. (A): bio-tofu with MTGase (BT-with MTGase); (B): bio-tofu without MTGase (BT-without MTGase). Numbered protein bands correspond to values of molecular mass $(\mathrm{kDa})$ found within the table. 


\section{Manuscript to be reviewed}

564 Fig.7 Degree of hydrolysis (DH) of digested samples at the gastric and duodenal steps

565 for the bio-tofu with MTGase (BT-with MTGase, ㅁ) and bio-tofu without MTGase

566 (BT-without MTGase, $\square$ ). Values are means \pm SD of three independent experiments

$567(\mathrm{n}=3)$. Different letters at the top of the bars indicate significant difference $(\mathrm{P}<0.05)$

568 between dairy samples at the end of each digestion phase.

569 
570 Table 1 In vitro digestibility of the bio-tofu with MTGase (BT-with MTGase) and

571 bio-tofu without MTGase (BT-without MTGase).

572

\begin{tabular}{cc}
\hline Sample & In vitro digestibility \\
\hline BT-with MTGase & $72.18 \pm 0.58^{\mathrm{b}}$ \\
BT-without MTGase & $74.65 \pm 0.75^{\mathrm{a}}$ \\
\hline
\end{tabular}

573

Mean values of digestibility that do not share the same letter are significantly different at $\mathrm{P}<0.05$. Triplicate samples were measured from duplication.

575

576

Table 2 Free amino acids contents of bio-tofu with MTGase (BT-with MTGase) and bio-tofu without MTGase (BT-without MTGase) at the end of in vitro GIS digestion. Results are expressed in milligrams per liter digestion solution. $\mathrm{ND}^{\mathrm{a}}=$ not determined

579

580

\begin{tabular}{ccc}
\hline & BT-with MTGase & BT-without MTGase \\
\hline Asp & 0.470 & 1.131 \\
Thr & 1.391 & 2.221 \\
Ser & 1.168 & 1.618 \\
Glu & 5.800 & 10.050 \\
Gly & 1.195 & 1.922 \\
Ala & 3.327 & 5.956 \\
Cys & 0.934 & 1.477 \\
Val & 0.286 & 0.207 \\
Met & ND $^{\mathrm{a}}$ & 0.127 \\
Ile & 0.100 & 0.149 \\
Leu & 2.047 & 3.352 \\
Tyr & 5.098 & 9.537 \\
Phe & 6.519 & 9.774 \\
Lys & 2.328 & 4.697 \\
His & 1.692 & 3.165 \\
Trp & 0.852 & 2.724 \\
Arg & 8.016 & 14.827 \\
Pro & 7.177 & 8.738 \\
Total & 13.523 & 23.251 \\
& 48.400 & 81.671 \\
\hline
\end{tabular}

581 


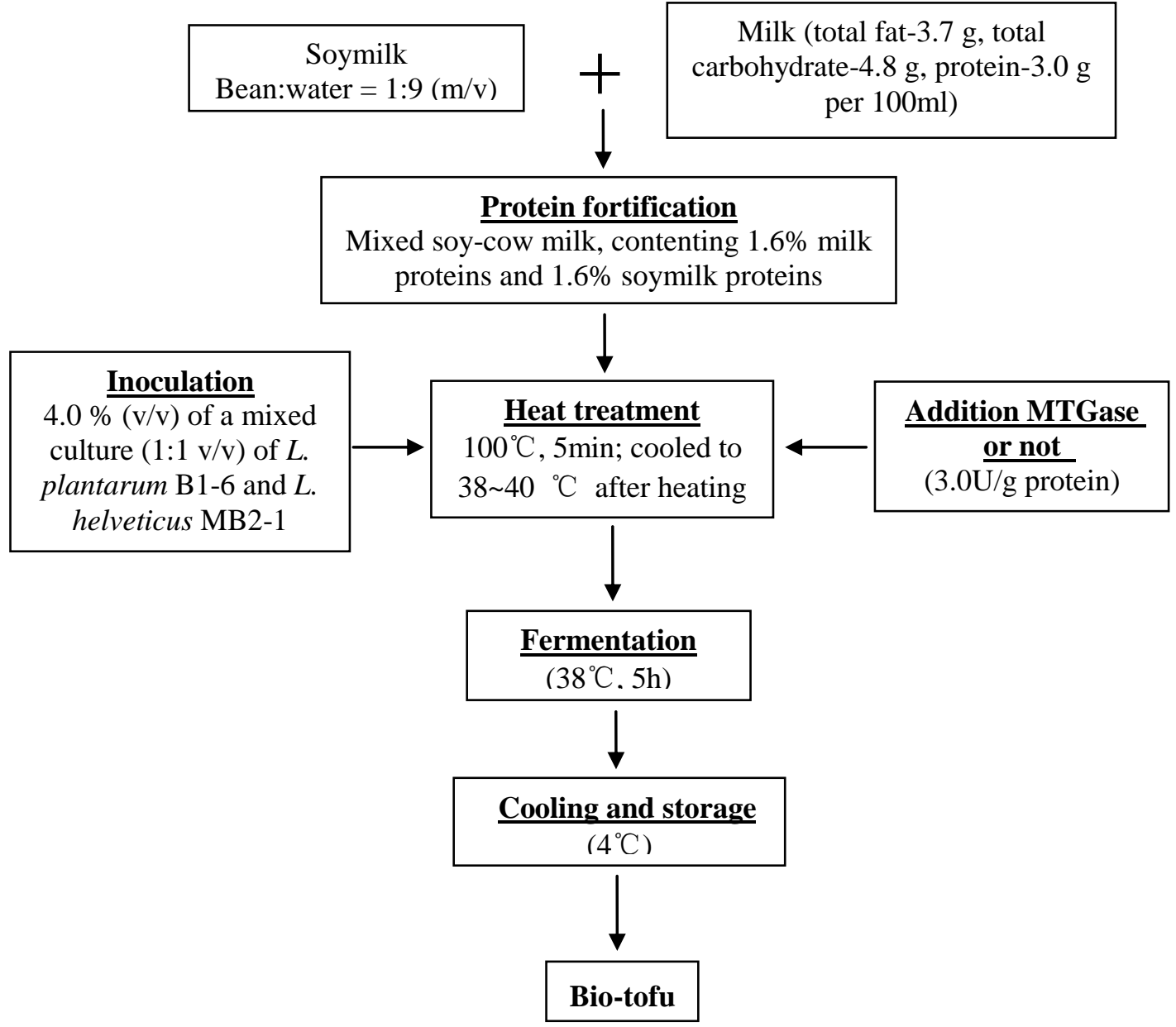

Fig. 1 


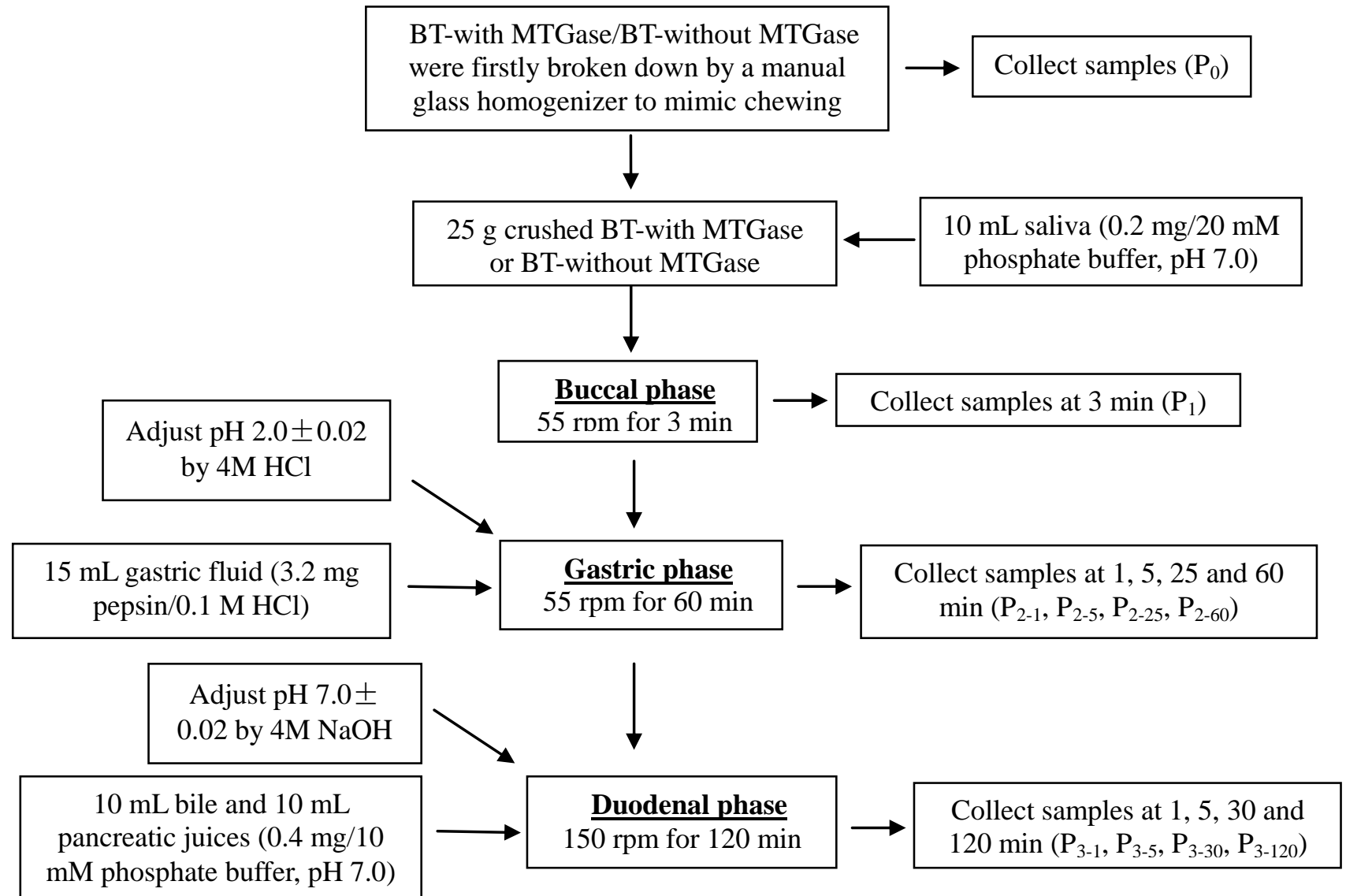

Fig. 2 
A

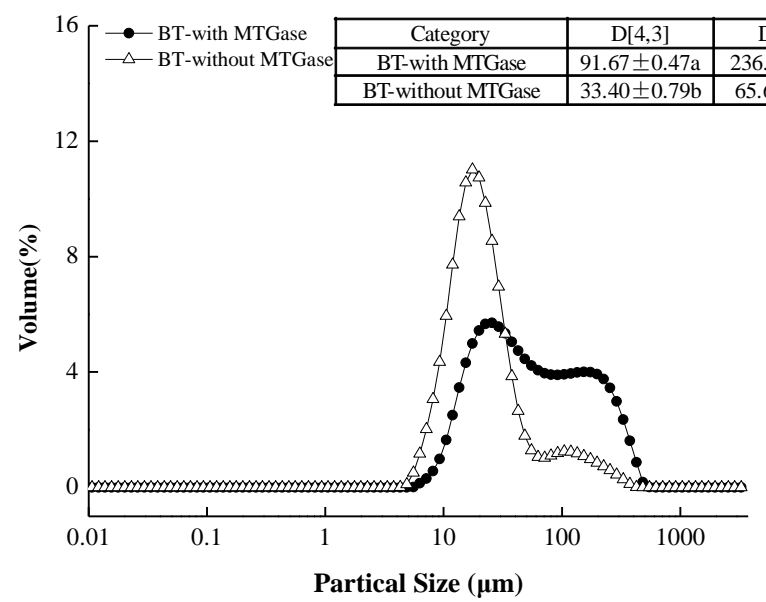

$\mathrm{C}$

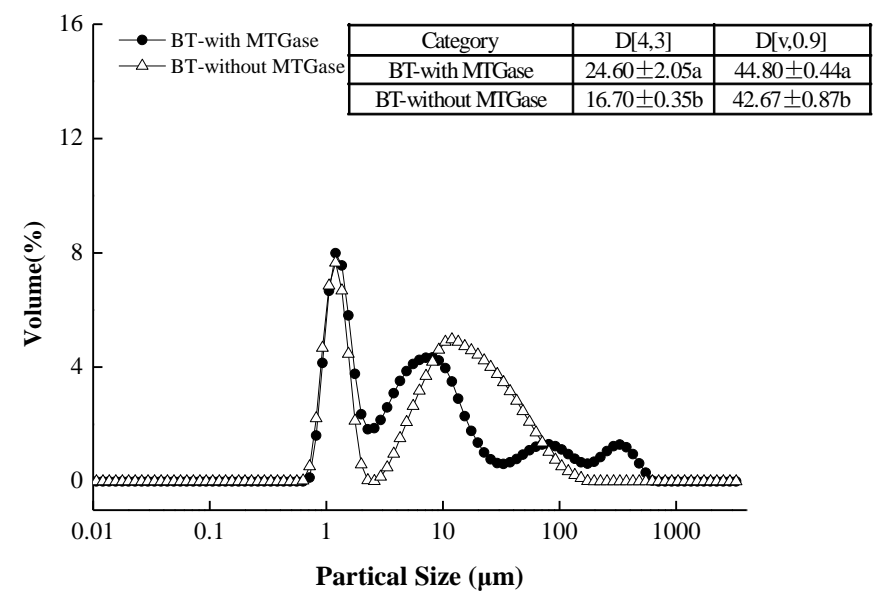

B

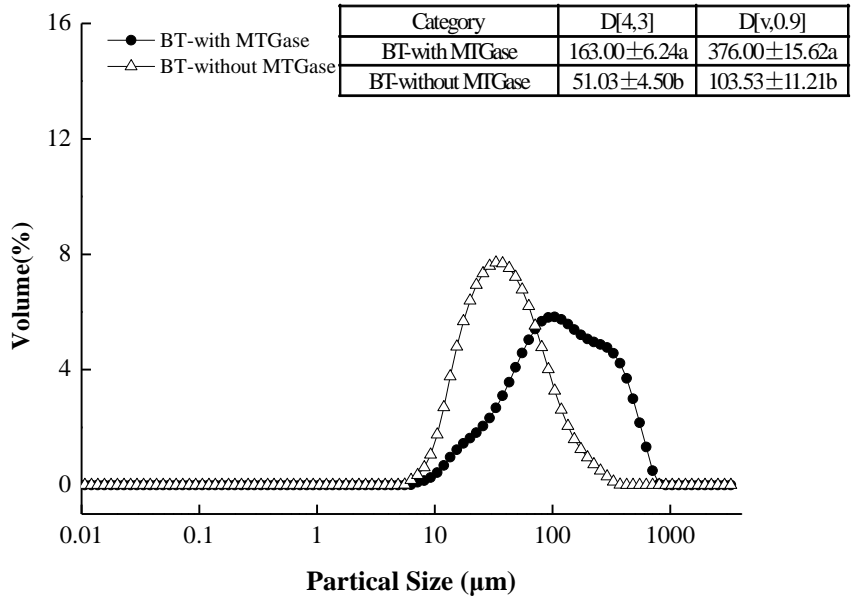

$\mathrm{D}$

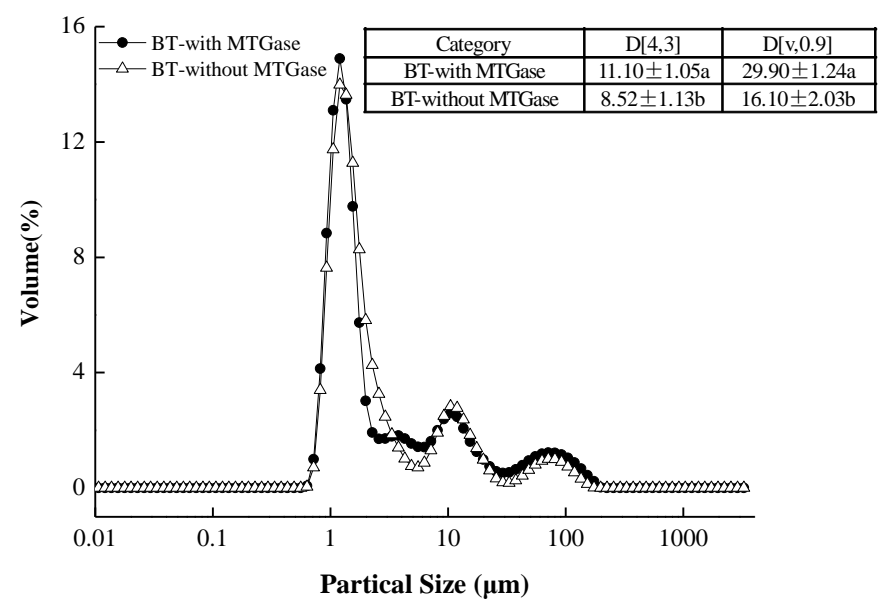

Fig. 3 


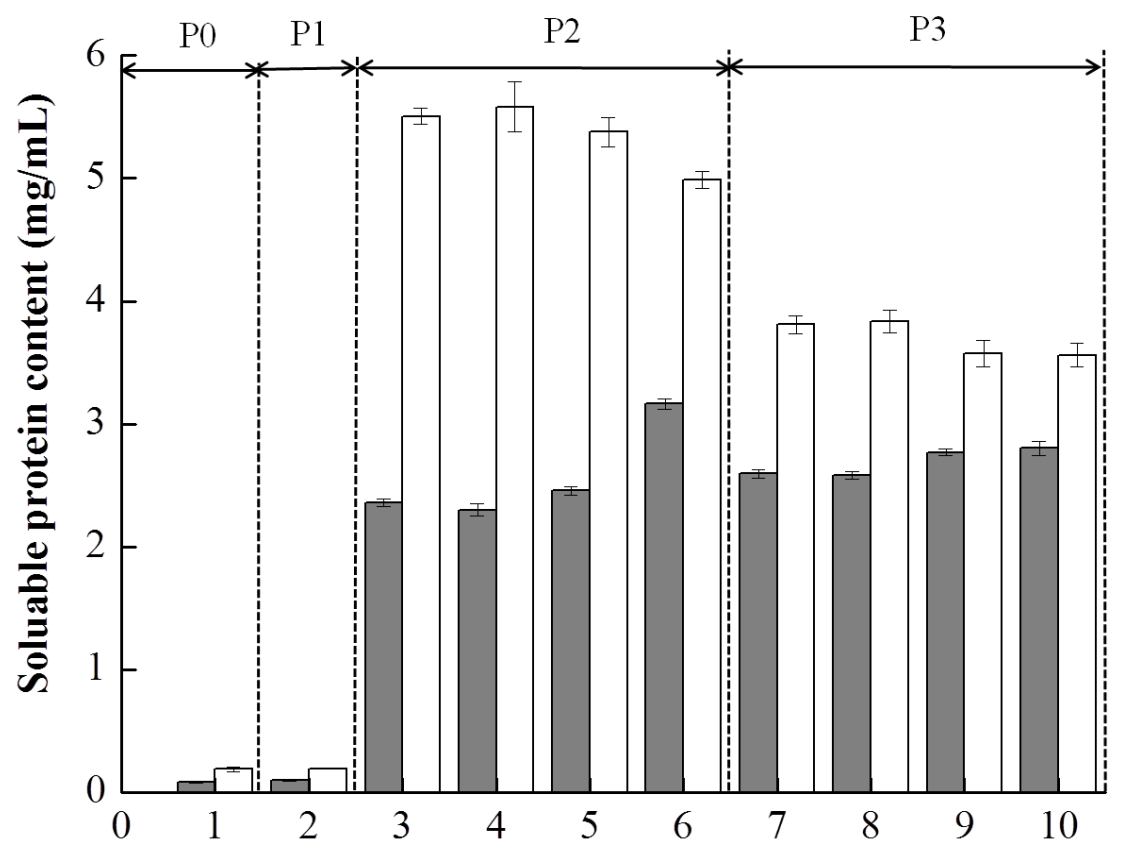

Fig. 4 

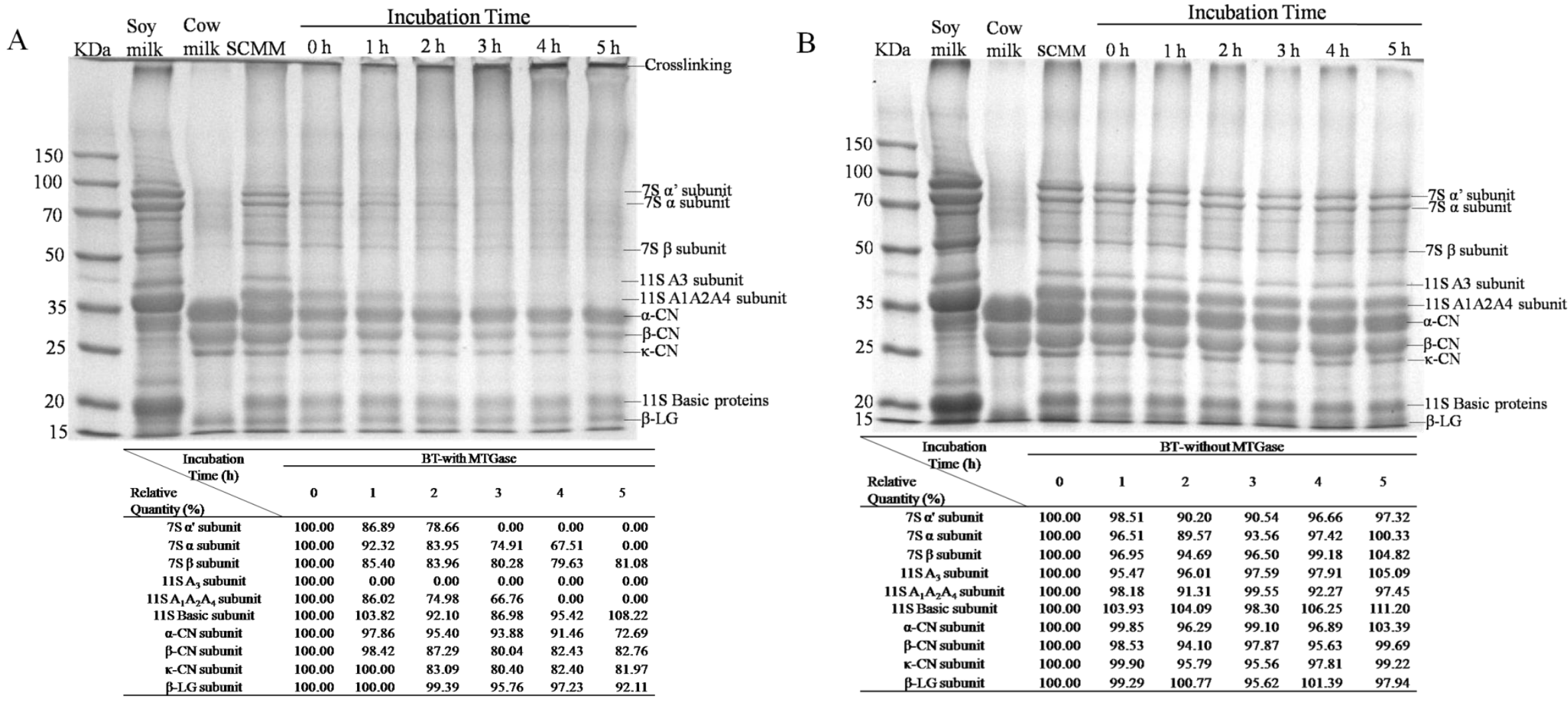

Fig. 5 

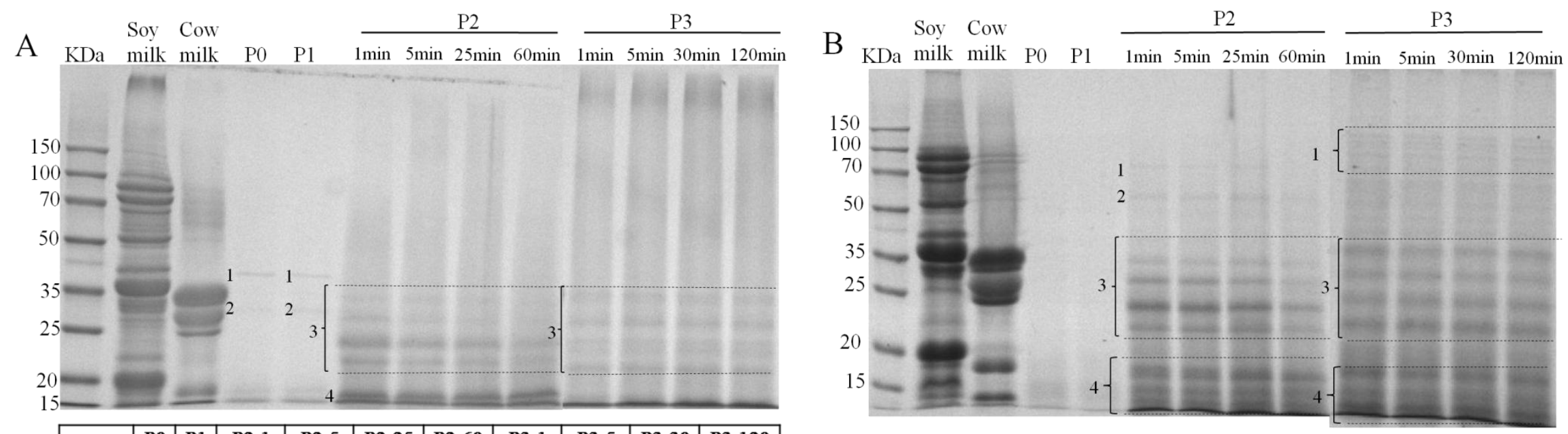

\begin{tabular}{|c|c|c|c|c|c|c|c|c|c|c|}
\hline & P0 & P1 & P2-1 & P2-5 & P2-25 & P2-60 & P3-1 & P3-5 & P3-30 & P3-120 \\
\hline Band\# & \multicolumn{10}{|c|}{ KDa } \\
\hline 1 & 38 & 38 & & & & & & & & \\
\hline 2 & 30 & 30 & & & & & & & & \\
\hline 3 & & & $22-33$ & $22-33$ & $22-33$ & $22-27$ & $21-30$ & $21-30$ & $21-30$ & $21-30$ \\
\hline 4 & & & 17 & 17 & 17 & 17 & & & & \\
\hline
\end{tabular}

\begin{tabular}{|c|c|c|c|c|c|c|c|c|c|}
\hline & \begin{tabular}{l|l|} 
P0 & P1 \\
\end{tabular} & P2-1 & P2-5 & P2-25 & P2-60 & P3-1 & P3-5 & P3-30 & P3-120 \\
\hline Band\# & \multicolumn{9}{|c|}{$\mathrm{KDa}$} \\
\hline 1 & & 76 & 76 & 76 & & $68-87$ & $68-87$ & $68-87$ & $68-87$ \\
\hline 2 & & 56 & 56 & 56 & 56 & & & & \\
\hline 3 & & $22-33$ & $22-33$ & $22-33$ & $22-33$ & $22-33$ & $22-33$ & $22-33$ & $22-33$ \\
\hline & & $13-17$ & 13-17 & & & $12-17$ & $12-17$ & $12-17$ & $12-17$ \\
\hline
\end{tabular}

Fig. 6 
595

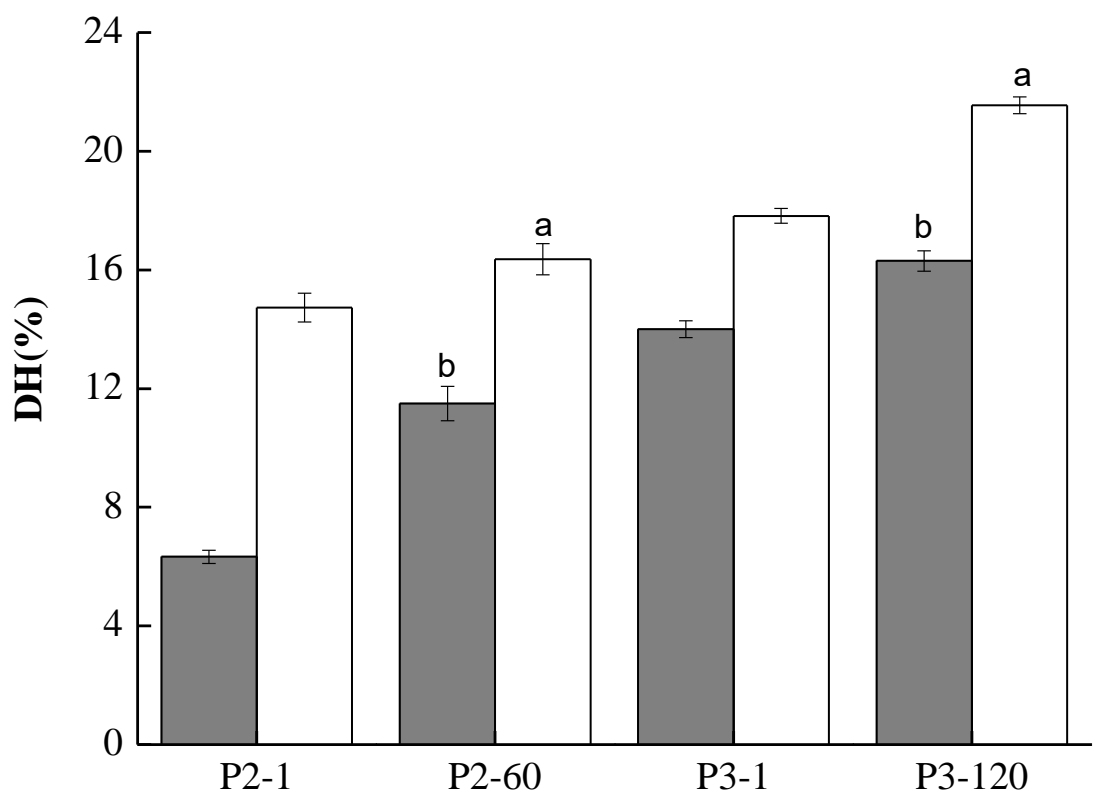

596

597

Fig. 7 